Article

\title{
Preparation of a Novel Lignin Nanosphere Adsorbent for Enhancing Adsorption of Lead
}

\author{
Chao Liu ${ }^{1,2} \mathbb{D}$, Youming $\mathrm{Li}^{1,2}$ and Yi Hou ${ }^{1,2, *}$ \\ 1 State Key Laboratory of Pulp and Paper Engineering, South China University of Technology, \\ Guangzhou 510640, China \\ 2 National Engineering Research Center of Papermaking and Pollution Control, South China University of \\ Technology, Guangzhou 510640, China \\ * Correspondence: ceyhou@scut.edu.cn \\ Academic Editors: Francesco Tornabene and Rossana Dimitri \\ Received: 25 June 2019; Accepted: 22 July 2019; Published: 25 July 2019

\begin{abstract}
Carboxymethyl lignin nanospheres (CLNPs) were synthesized by a two-step method using microwave irradiation and antisolvent. The morphology and structure of CLNPs were characterized by ${ }^{31}$ P-NMR, FTIR, and SEM, and the results showed that they had an average diameter of $73.9 \mathrm{~nm}$, a surface area of $8.63 \mathrm{~m}^{2}$ or 3.2 times larger than the original lignin, and abundant carboxyl functional groups of $1.8 \mathrm{mmol} / \mathrm{g}$. The influence of dosage, $\mathrm{pH}$, contact time, and concentration on the adsorption of metal ions onto CLNPs were analyzed, and the maximum adsorption capacity of CLNPs for $\mathrm{Pb}$ (II) was found to be $333.26 \mathrm{mg} / \mathrm{g}$, which is significantly higher than other lignin-based adsorbents and conventional adsorbents. Adsorption kinetics and isotherms indicated that the adsorption of lead ions in water onto CLNPs followed the pseudo-second-order model based on monolayer chemisorption mechanism. The main chemical interaction between CLNPs and lead ions was chelation. CLNPs also showed an excellent recycling performance, with only $27.0 \%$ adsorption capacity loss after 10 consecutive adsorption-desorption cycles.
\end{abstract}

Keywords: lignin; carboxymethyl; nanosphere; adsorption; lead

Academic Editors: Francesco Tornabene and Rossana Dimitri

\section{Introduction}

Heavy metal ions in water can be transmitted and enriched in the food chain in the ecosystem, posing a threat to the surrounding environment and to human health [1]. Toxic heavy metals, such as lead $(\mathrm{Pb})$, copper $(\mathrm{Cu})$, cadmium $(\mathrm{Cd})$, nickel $(\mathrm{Ni})$, chromium $(\mathrm{Cr})$, and zinc $(\mathrm{Zn})$, have been classified as major pollutants, which cause numerous diseases and disorders at even very low levels. Therefore, toxic heavy metal ions must be removed from wastewater effluent before being discharged into the environment. The removal of heavy metals by electrochemical treatment, adsorption, membrane technology, and other effective methods has been extensively studied [2-4]. In recent years, various highly efficient materials, such as carbon nanotubes, activated carbon, graphene, molecular sieves, and polymer materials, have been used as adsorbents for wastewater purification and been widely commercialized [5-7]. However, due to its high cost, poor adsorption capacity, and poor regeneration performance, its industrial application is limited [6,8]. These limitations have prompted a search for low-cost and efficient adsorbents as replacements.

Lignin is the second most abundant natural polymer in lignocellulosic biomass (15-30 wt \%) next to cellulose [9]. At least 50 million tons of industrial lignin is produced annually from the pulp and paper industry, but less than $2 \%$ of the lignin is separated from black liquor and transformed into other high-value products $[10,11]$. In fact, the combination of abundance, biodegradability, low cost, and abundant active groups of lignin makes it a promising raw material for the preparation of 
adsorbents [12,13]. However, the adsorption capacity of lignin adsorbents for metal ions is low, such as $9.0 \mathrm{mg} / \mathrm{g}$ for $\mathrm{Pb}$ (II), $7.5 \mathrm{mg} / \mathrm{g}$ for $\mathrm{Cd}$ (II), $26 \mathrm{mg} / \mathrm{g}$ for $\mathrm{Cu}$ (II), and $17.97 \mathrm{mg} / \mathrm{g}$ for $\mathrm{Cr}$ (III) [6,14], which limits their practical application in the treatment of water that is contaminated with heavy metals.

At present, the method for increasing the adsorption of lignin is mainly lignin modification or increasing the specific surface area of lignin. Dizhbite et al. [15] studied the introduction of oxygen-containing groups by oxidative modification of organic solvent lignin from wheat straw. After modification, the $\mathrm{COOH}$ content of lignin increased significantly. At $\mathrm{pH} 5.0$ and $20{ }^{\circ} \mathrm{C}$, the saturated adsorption capacity of the modified lignin $\mathrm{Pb}(\mathrm{II})$ reached $155.4 \mathrm{mg} / \mathrm{g}$. Peternele et al. [16] reported a carboxymethyl-formate-modified lignin with a saturated adsorption capacity of $107.5 \mathrm{mg} / \mathrm{g}$ for $\mathrm{Pb}$ (II). Li et al. [17] prepared a lignosulfonate-based porous lignin microsphere, but its adsorption capacity for heavy metal lead was only $27.1 \mathrm{mg} / \mathrm{g}$. The lignin microspheres prepared by Ge et al. [8] had a diameter of $348 \mu \mathrm{m}$, a specific surface area of $9.6 \mathrm{~m}^{2} / \mathrm{g}$ or 5.3 times that of the original lignin, and an adsorption capacity of $33.9 \mathrm{mg} / \mathrm{g}$ for $\mathrm{Pb}(\mathrm{II})$. There is an urgent need to develop a new method for the synthesis of lignin that can increase the specific surface area of lignin based on the completion of lignin modification. In our previous work, ionic liquids (ILs) were used as "green solvents" for the formation of alkali lignin nanospheres (ALNPs). The method involved the preparation of lignin nanospheres at high concentration, which could effectively improve the yield of lignin nanospheres [18]. Compared with traditional adsorbents, nanospheres have larger surface area and better diffusion, dispersion, and mass transfer behavior. Meanwhile, many studies have shown that, in addition to phenolic hydroxyl groups, alcoholic hydroxyl groups can also be reacted with sodium monochloroacetate under microwave irradiation for alkali lignin (AL) $[19,20]$. However, to date, there have been no reports on carboxyl-modified lignin nanospheres.

In this study, we report on a novel lignin nanosphere with abundant carboxyl functional groups, which has the advantages of a simple preparation method, strong adsorption capacity for lead ions, and recyclability. The lignin nanospheres, which were prepared using ionic liquid and antisolvent, greatly reduced the water solubility of carboxyl-modified lignin and improved the chelating ability of carboxyl with heavy metal ions (Figure 1). We also studied the carboxyl content and chemical structure of the modified lignin. The adsorption of lead(II) on carboxymethyl lignin nanospheres (CLNPs) was studied by controlling the $\mathrm{pH}$, reaction time, adsorbent dosage, and initial concentration. The adsorption mechanism was studied by analyzing adsorption thermodynamic, isotherms, and kinetic parameters. Moreover, the performance of the adsorbent was compared with that of some existing adsorbents.
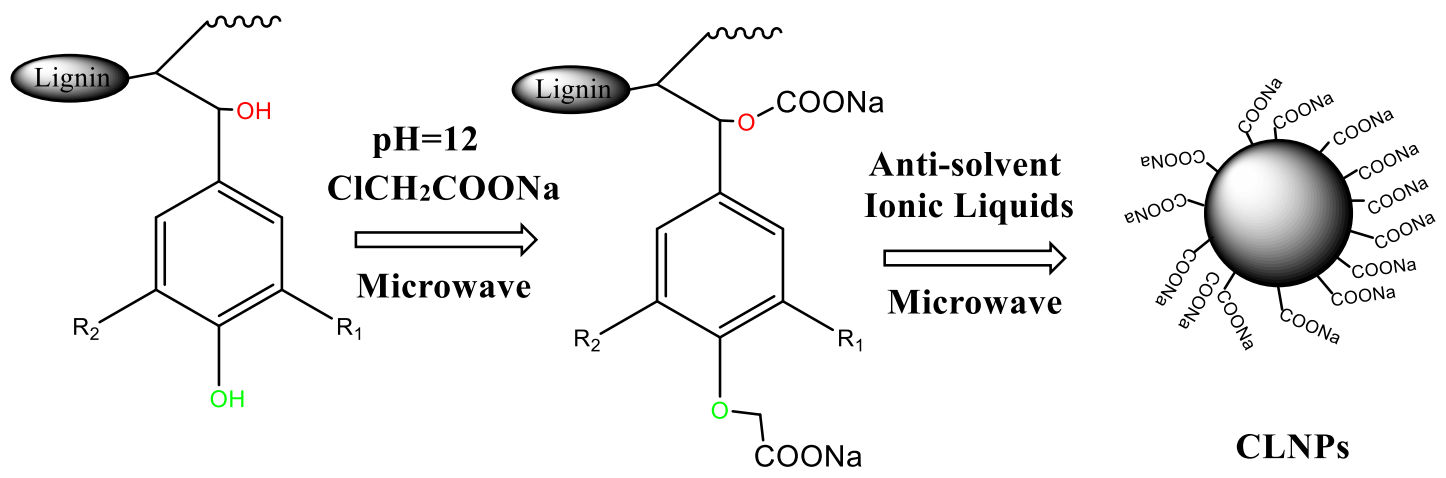

Figure 1. Schematic diagram showing the two-step synthesis of carboxymethyl lignin nanospheres (CLNPs).

\section{Experimental}

\subsection{Materials}

1-methylimidazole (>99 wt \%, Acros, Guangzhou, China), bromoethane (>99 wt \%, Aladdin, Guangzhou, China) and ethyl acetate (>99.9 wt\%, Aladdin, Guangzhou, China) were used to prepare 
ionic liquids [EMIM][Ac] in-house according to a procedure available in the literature [21]. Lignin (alkali lignin, $\geq 99 \%$ purity) and sodium monochloroacetate were purchased from Sigma-Aldrich (Beijing, China). All chemicals used were of analytical reagent grade.

\subsection{Preparation of CLNPS}

CLNPs were prepared by a two-step method that involved synthesizing carboxyl-modified AL and preparing carboxymethyl lignin nanospheres. For the first step, $1.5 \mathrm{~g}$ alkali lignin, $1.17 \mathrm{~g}$ sodium monochloroacetate, and $0.4 \mathrm{~g}$ sodium hydroxide were dissolved in $30 \mathrm{~mL}$ distilled water under stirring. After that, the mixtures were reacted in a microwave device (XH-100B, XINGHU Microwave Beijing, China) and then microwave-treated for $30 \mathrm{~min}$ at $95{ }^{\circ} \mathrm{C}$. The $\mathrm{pH}$ of the solution was adjusted to neutral with dilute sulfuric acid. It was then filtered and washed by deionized water and dried under vacuum at $50{ }^{\circ} \mathrm{C}$ for $24 \mathrm{~h}$. For the second step, $1 \mathrm{~g}$ carboxymethyl lignin was dissolved in $10 \mathrm{~mL}$ [Emim][Ac] using a microwave catalytic synthesis extractor. The dissolving conditions were as follows: microwave power, $500 \mathrm{~W}$; temperature, $80^{\circ} \mathrm{C}$; reaction time, $30 \mathrm{~min}$. Then, the solution was stirred at room temperature $\left(25^{\circ} \mathrm{C}\right)$ with magnetic stirring speed of about $600 \mathrm{rpm}$. After these steps, acid water $(\mathrm{pH}=2-3$ ) was gradually added into the solution at the speed of $3 \mathrm{~mL} / \mathrm{min}$ to $80 \mathrm{vol} \%$, and stirring was continued for $60 \mathrm{~min}$ to form CLNPs. After particle formation and solvent removal, the particles were centrifuged at $9000 \mathrm{rpm}$ for $10 \mathrm{~min}$ and washed twice with deionized water. Finally, CLNP was freeze-dried and stored in a sealed vial.

\subsection{Characterizations}

To measure the carboxyl group content of the lignin samples, ${ }^{31} \mathrm{P}-\mathrm{NMR}$ was carried out using Bruker AVANCE 600 NMR spectrometer (Bruker, Karlsruhe, Germany) according to existing research methods [22]. FTIR, SEM, and the size of CLNPs were tested in our previous study [18]. The Brunauer-Emmett-Teller (BET) method was utilized to calculate the surface area [23]. X-ray photoelectron spectroscopy (XPS) was applied on a polycrystalline X-ray diffraction instrument (D8 ADVANCE, Karlsruhe, Germany). Binding energy values were calibrated using characteristic carbon $(\mathrm{C} 1 \mathrm{~s}=284.8 \mathrm{eV})$ during data processing of XPS spectra.

\subsection{Adsorption}

$\mathrm{Pb}$ (II) adsorption onto CLNPs was measured by mixing CLNPs with aqueous solutions. All experiments were conducted in a $150 \mathrm{~mL}$ conical flask containing $50 \mathrm{~mL}$ of a $\mathrm{Pb}$ (II) solution that was placed in a constant temperature oscillator at $30 \pm 2{ }^{\circ} \mathrm{C}$. Then, the supernatant was removed by filtration. The filtrate was analyzed by a Z-2000 atomic absorption spectrophotometer. All adsorption experiments were performed three times, and the average was calculated to avoid any experimental error. The removal efficiency $(E)$ and adsorption amount $\left(Q_{e}\right)$ were calculated by the following equations:

$$
\begin{gathered}
E(\%)=\frac{C_{0}-C_{e}}{C_{0}} \times 100 \\
Q_{e}(\mathrm{mg} / \mathrm{g})=\frac{C_{0}-C_{e}}{m} \times \mathrm{V}
\end{gathered}
$$

where $C_{0}$ and $C_{e}$ are the initial and final concentration of $\mathrm{Pb}(\mathrm{II})(\mathrm{mg} / \mathrm{L})$, respectively; $\mathrm{V}$ is the volume of $\mathrm{Pb}$ (II) solution (ml); and $m$ is the mass of CLNPs (g). After adsorption of the metal ions, the lead-loaded CLNPs were desorbed in $\mathrm{HNO}_{3}(0.1 \mathrm{M})$ solution for $4 \mathrm{~h}$ at $25^{\circ} \mathrm{C}$. Then, it was neutralized by $\mathrm{NaOH}(0.1$ $\mathrm{M})$, filtered and washed with deionized water until the $\mathrm{pH}$ remained constant, and then lyophilized. The regenerated CLNP sample was used for a further adsorption-desorption test of 10 cycles to investigate its recyclability. 


\section{Results and Discussion}

\subsection{Characterizations}

NMR analysis was performed to detect the carboxyl group content of the functional group. The corresponding NMR signal of AL and CLNPs is shown in Figure 2. The corresponding quantitative results of the functional group are shown in Table 1. The carboxyl contents of AL and CLNPs were 0.95 and $1.80 \mathrm{mmol} / \mathrm{g}$, respectively. This effectively increased the carboxyl content of the product, which was 0.90 times higher than that of AL. It can also be seen from Table 1 that sodium monochloroacetate mainly reacted with the phenolic hydroxyl group in the alkali lignin during microwave irradiation, which is consistent with reports in the related literature [20]. From the FTIR spectra (Figure 3), the strength of $1710 \mathrm{~cm}^{-1}$ was attributed to the carboxyl group. Compared with AL and ALNPs, CLNPs had more obvious chemical information of carboxyl functional groups. The bands at $1510 \mathrm{~cm}^{-1}$ represented the aromatic skeletal vibrations, which indicated that the aromatic structure of lignin was not damaged during the synthesis of carboxyl-modified lignin nanospheres. The FTIR analysis agreed well with the results of the NMR analysis. This also proves that the microwave-assisted synthesis of carboxyl-modified lignin nanospheres can not only improve the reaction efficiency in a short time but also retain the original benzene ring structure of the alkali lignin.

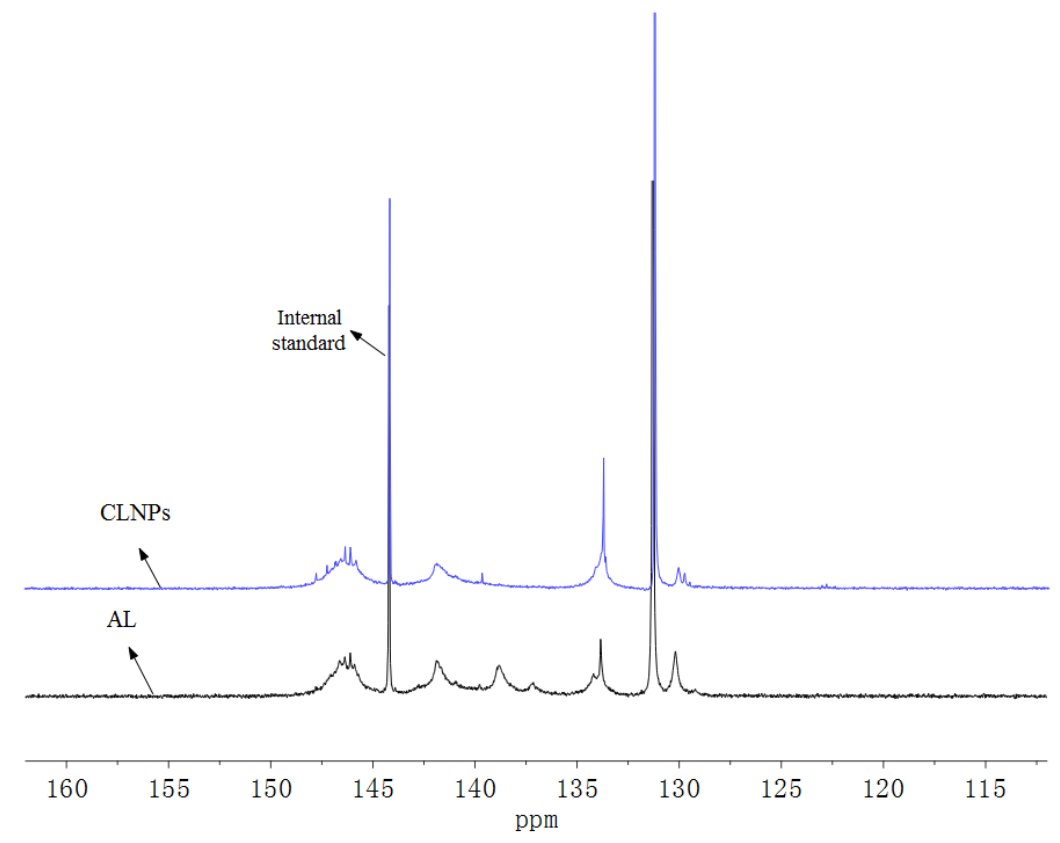

Figure 2. Quantitative ${ }^{31}$ P-NMR spectra of the alkali lignin (AL) and CLNPs.

Table 1. The contents of functional groups in AL and CLNPs.

\begin{tabular}{cccccc}
\hline Lignin & $\begin{array}{c}\text { Aliphatic OH } \\
(\mathbf{1 5 0 - 1 4 5 . 7} \mathbf{p p m})\end{array}$ & $\begin{array}{c}\text { Condensed Phenolic } \\
\text { OH (145-140.7 } \mathbf{p p m})\end{array}$ & $\begin{array}{c}\text { Guaiacyl and Catechol } \\
\text { OH (140-137.6 ppm) }\end{array}$ & $\begin{array}{c}\text { Total Phenolic } \\
\text { OH }\end{array}$ & $\begin{array}{c}\text { Carboxyl } \\
\mathbf{( 1 3 6 - 1 3 3 . 8} \mathbf{p p m})\end{array}$ \\
\hline \multirow{2}{*}{ AL } & $(\mathrm{mmol} / \mathrm{g})$ & $(\mathrm{mmol} / \mathrm{g})$ & $(\mathrm{mmol} / \mathrm{g})$ & $(\mathrm{mmol} / \mathrm{g})$ & 3.18 \\
CLNPs & 2.32 & 1.76 & 1.42 & 2.03 & 0.95 \\
\hline
\end{tabular}




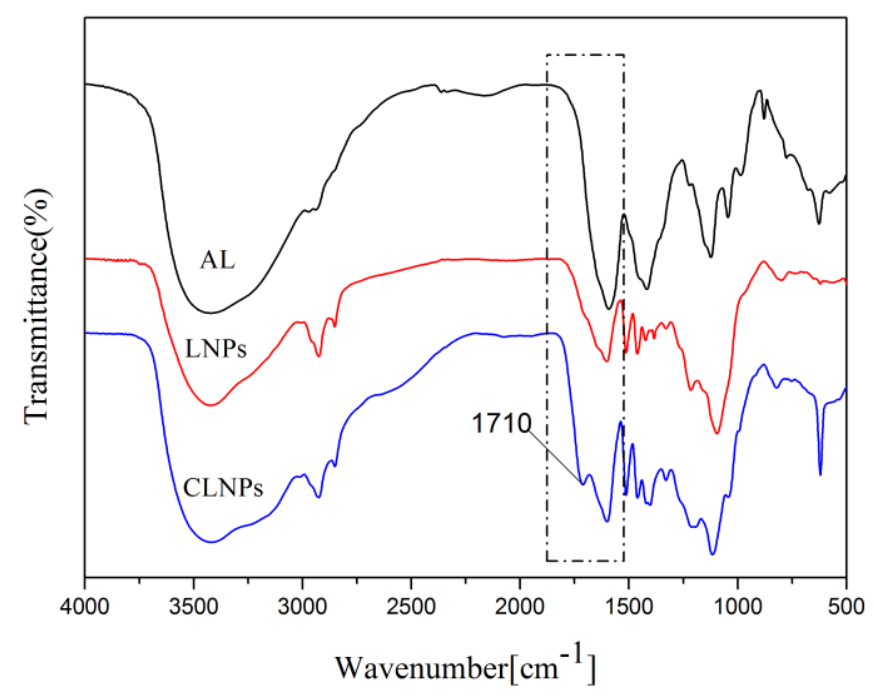

Figure 3. IR spectra of AL, lignin nanospheres (LNPs), and CLNPs.

The morphology of CLNPs was observed by SEM. As shown in Figure 4, the CLNPs were found to be uniformly spherical. The average particle size of nanospheres, as determined by dynamic laser light scatterometer, was approximately $73.9 \mathrm{~nm}$ (Figure 5A). The surface area of CLNPs was determined by the BET method from the $\mathrm{N}^{2}$ adsorption isotherm, as shown in Figure 5B. The $\mathrm{S}_{\mathrm{BET}}$ of CLNPs was $8.63 \mathrm{~m}^{2} / \mathrm{g}$, which was 3.2 times that of lignin $\left(2.72 \mathrm{~m}^{2} / \mathrm{g}\right)$. The large surface area is beneficial for the adsorption of lead in wastewater.
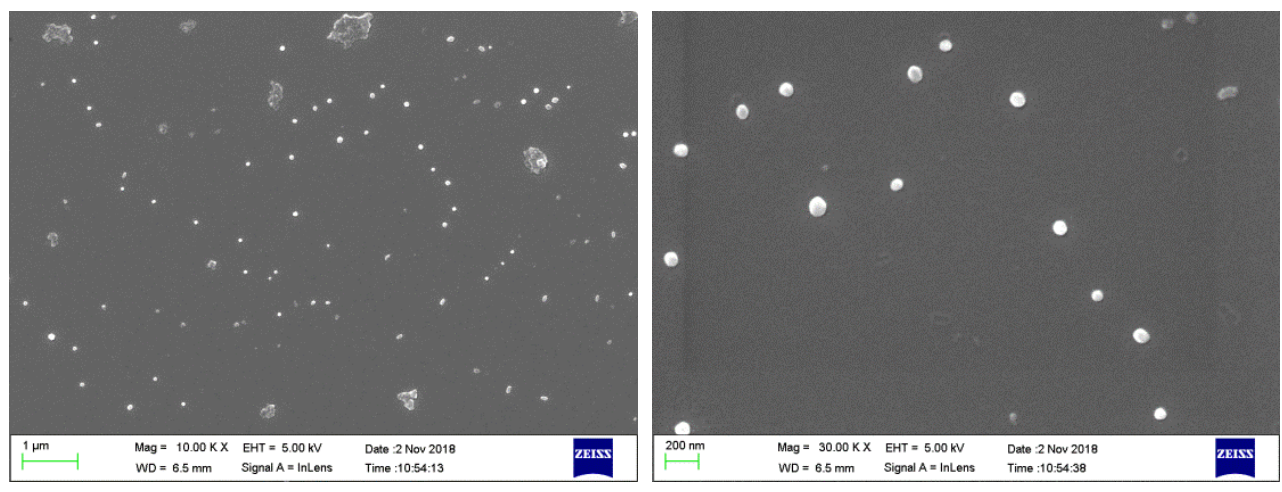

Figure 4. SEM images of CLNPs.

Previous studies have suggested that lignin has a strong self-assembly capability [24]. According to our group's previous research, they coexist in the form of single molecules and aggregate in solution. After the antisolvent is added to the solution, the hydrophobic chains of the complexes continue to aggregate to form a stable nanoparticle core [18]. This process should result in a bimodal distribution of particle size unless it reaches the equilibrium, which requires a very long time. Interestingly, the ionic liquid molecules with a weaker hydrophobicity are still dispersed in solution [18]. With improved antisolvent, nanospheres composed of a hydrophilic shell and a hydrophobic core are formed. The self-assembly method largely reduces the water solubility of the nanospheres, so more carboxyl group-containing functional groups are exposed on the surface of the nanospheres. 

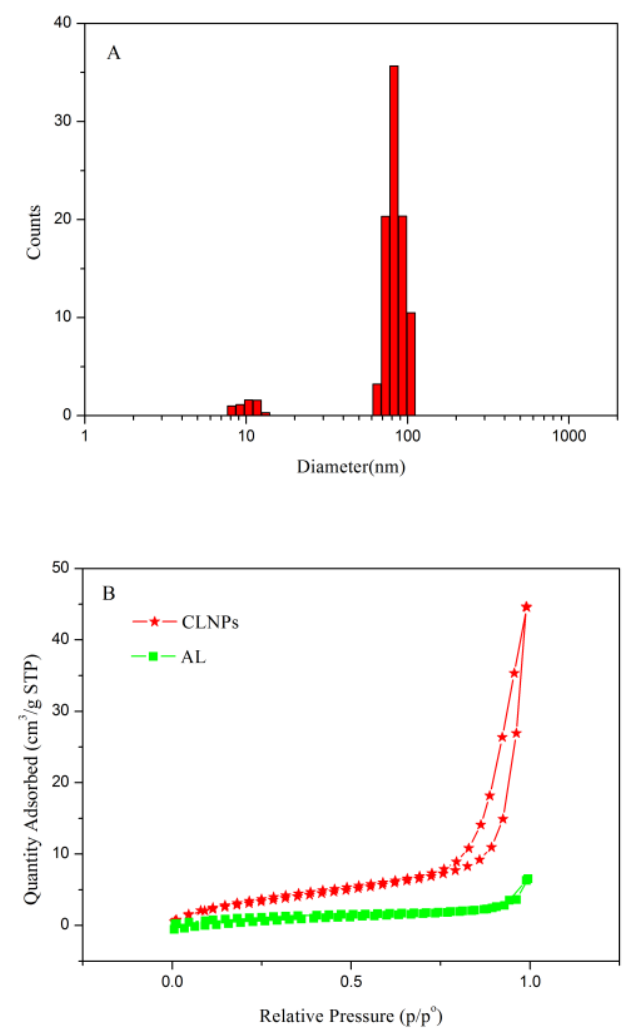

Figure 5. Particle size distribution of CLNPs (A) and nitrogen adsorption-desorption isotherms (B).

\subsection{Adsorption Studies}

The $\mathrm{pH}$ of the solution affects the presence and solubility of heavy metal ions in water. The $\mathrm{pH}$ affects the surface charge and the extent of functional stratification of the adsorbent material, and the $\mathrm{pH}$ of the solution plays an important role in the adsorption of metal ions. The removal efficiency of heavy metal ions by CLNPs and LNPs was examined within the $\mathrm{pH}$ efficiency of 2.04-7.06, and the results are depicted in Figure 6. As can be seen, the adsorption amount of CLNPs was significantly higher than that of LNPs, and the adsorption capacity increased until the $\mathrm{pH}$ increased to 6.03. When the $\mathrm{pH}$ was low, too many hydrogen ions in the solution protonated the carboxyl group of CLNPs to form -COOH, which weakened the electrostatic attraction and complexing ability between the carboxyl group and the heavy metal ion, thereby reducing the adsorption amount. The carboxyl group on the CLNPs deprotonated further with the increase in $\mathrm{pH}$ value, and $\mathrm{COO}^{-}$was combined with heavy metal ions to increase the adsorption amount. At $\mathrm{pH}=6.03$, the adsorption capacity of CLNPs $(217.21 \mathrm{mg} / \mathrm{g})$ was 4.2 times higher than LNPs ( $51.67 \mathrm{mg} / \mathrm{g}$ ). Furthermore, it is worth noting that when the $\mathrm{pH}$ exceeds the $\mathrm{pH}$ threshold $(>6)$ of $\mathrm{Pb}(\mathrm{OH})_{2}$ precipitation, the removal process is a combination of precipitation of $\mathrm{Pb}(\mathrm{OH})_{2}$ and adsorption [25]. Therefore, to avoid the formation of metal hydroxide precipitation, $\mathrm{pH}$ $=6.03$ was chosen for further adsorption test. 


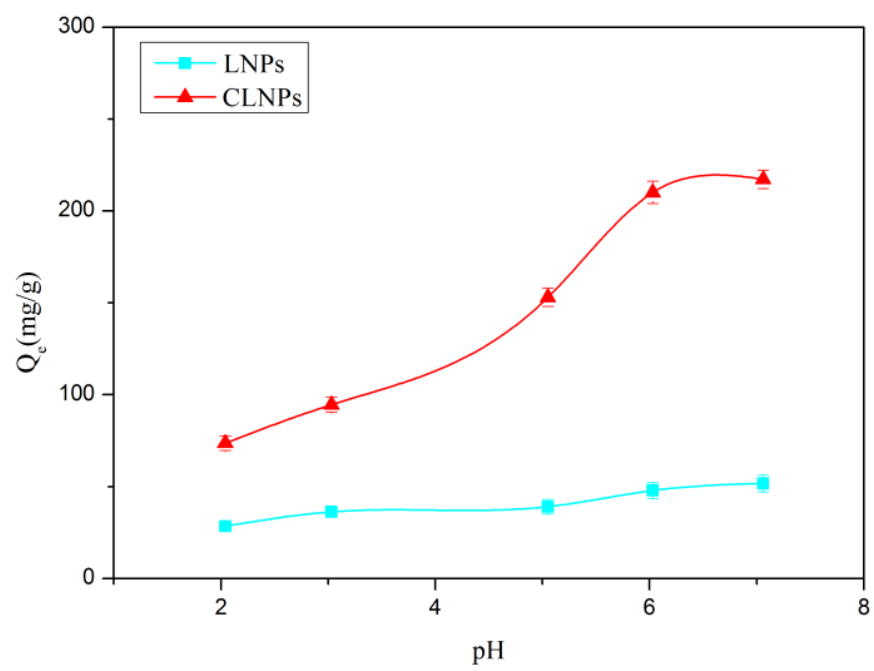

Figure 6. Effect of $\mathrm{pH}$ on the adsorption amount of $\mathrm{Pb}$ (II) by CLNPs and LNPs (dosage $=10 \mathrm{mg} / 50 \mathrm{~mL}$, $C_{0}=100 \mathrm{mg} / \mathrm{L}, \mathrm{t}=180 \mathrm{~min}$, temperature $=30^{\circ} \mathrm{C}$ ).

The effect of CLNPs dosage on adsorption metal ions at $\mathrm{pH}=6.03$ was also studied. The test was carried out under conditions of an initial lead ion concentration of $100 \mathrm{mg} / \mathrm{L}$ for $180 \mathrm{~min}$. As shown in Figure 7, the adsorption capacity of CLNPs initially increased with CLNPs loading and reached $333.26 \mathrm{mg} / \mathrm{g}$ at $0.3 \mathrm{~g} / \mathrm{L}$. As the adsorption dosage was further increased, the adsorption capacity began to decrease. Initially, as the amount of CLNPs increased, the increase in adsorption capacity was due to an increase in the effective adsorption sites on the surface of the adsorbent. In contrast, as the initial amount of lead ions was kept constant, the adsorption amount of $\mathrm{Pb}$ (II) decreased with an increase in the adsorbent dosage. This might have been due to an increase in the CLNPs dose, which resulted in a more unsaturated adsorption site on the surface of the adsorbent, thereby resulting in a decrease in adsorption capacity.

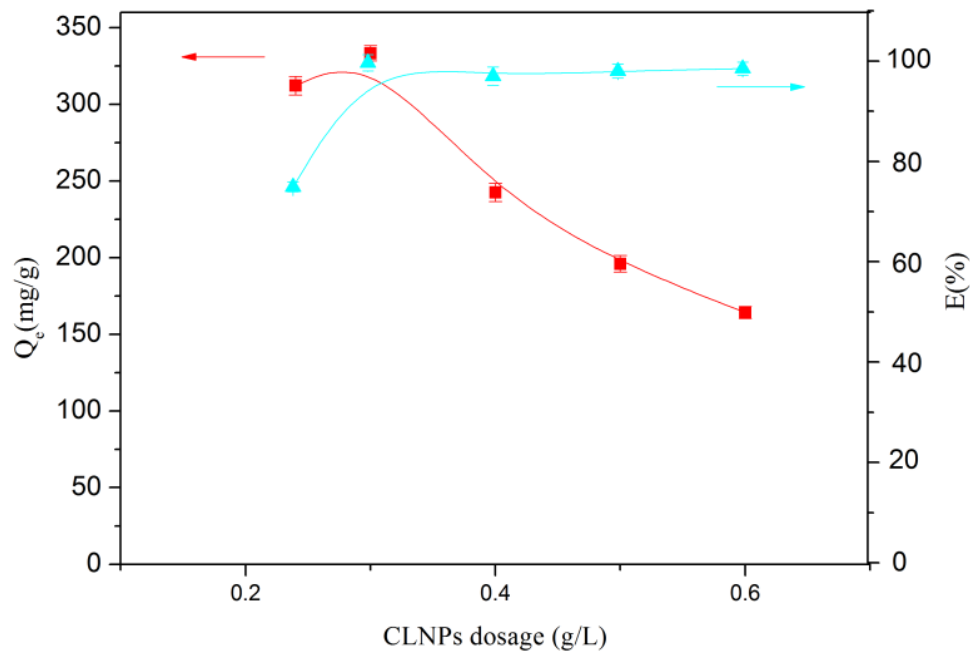

Figure 7. Effect of dosage on the adsorption of $\mathrm{Pb}(\mathrm{II})$ on CLNPs $\left(C_{0}=100 \mathrm{mg} / \mathrm{L}, \mathrm{t}=180 \mathrm{~min}\right.$, temperature $=30^{\circ} \mathrm{C}, \mathrm{pH}=6.03$ ).

Adsorption kinetics were studied $\left(C_{0}=100 \mathrm{mg} / \mathrm{L}, 30^{\circ} \mathrm{C}, \mathrm{CLNP}\right.$ dosage of $\left.15 \mathrm{mg} / 50 \mathrm{~mL}, \mathrm{pH}=6.03\right)$ to determine the equilibrium time and adsorption rate. As illustrated in Figure 8, the results showed that the adsorption of metal ions increased sharply at the beginning and reached saturation within 180 $\mathrm{min}$. The initial rapid adsorption was due to the availability of the initial large number of vacancies and the chelating force for mass transfer. Subsequently, the filling of the vacancies became difficult 
owing to the repulsive force between the $\mathrm{Pb}(\mathrm{II})$ adsorbed on the surface of the nanosphere and the $\mathrm{Pb}$ (II) in the bulk solution [8]. As shown in Table 2, the saturated adsorption capacity of CLNPs was $333.26 \mathrm{mg} / \mathrm{g}$, which is much higher than other lignin-based adsorbents and conventional adsorbents, such as those shown in Table 2. The high adsorption capacity might have been due to its large surface area and large amount of accessible carboxyl groups.

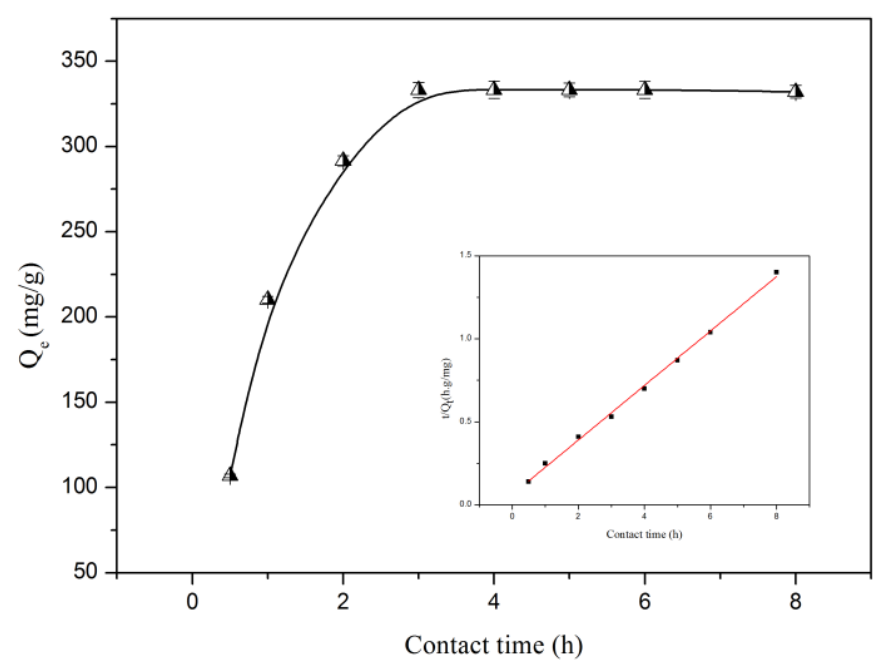

Figure 8. Kinetic adsorption results of $\mathrm{Pb}(\mathrm{II})$ on CLNPs. The inset shows the fitting results of the pseudo-second-order model for $\mathrm{Pb}$ (II) adsorption (CLNP dosage $=15 \mathrm{mg} / 50 \mathrm{~mL}, \mathrm{C}_{0}=100 \mathrm{mg} / \mathrm{L}$, temperature $=30^{\circ} \mathrm{C}, \mathrm{pH}=6.03$ ).

The kinetic data were also analyzed by the pseudo-first-order (Equation (3)) [26] and pseudo-second-order kinetic models (Equation (4)) [27]:

$$
\begin{gathered}
\log \left(Q_{e}-Q_{t}\right)=\log Q_{e}-\frac{K_{1}}{2.303} t \\
\frac{t}{Q_{t}}=\frac{1}{K_{2} Q_{e}^{2}}+\frac{t}{Q_{e}}
\end{gathered}
$$

where $Q_{t}$ and $Q_{e}$ are the amounts of metal ions adsorbed $(\mathrm{mg} / \mathrm{g})$ at contact time $t$ (min) and at equilibrium, respectively; $k_{1}\left(1 \mathrm{~min}^{-1}\right)$ and $k_{2}(\mathrm{~g} / \mathrm{mg} \mathrm{min})$ are the rate constants. The kinetic process of $\mathrm{Pb}$ (II) in water by CLNPs is shown in Figure 8 and Table 3 . It can be observed that the $Q_{e}$ calculated by the pseudo-first-order model did not match the experimental adsorption amount, and the $R^{2}$ value was very low (0.6013). This indicates that the first-order model cannot describe the adsorption kinetics. For the pseudo-second-order model, the calculated $Q_{e}(350.9 \mathrm{mg} / \mathrm{g})$ was close to the experimental value, and a higher correlation coefficient $\left(R^{2}=0.9991\right)$ was obtained. This suggests that the adsorption followed pseudo-second-order kinetics. The pseudo-second-order is based on the chemical adsorption between the metal ion and the active sites of the adsorbent [25]. The results show that the adsorption of $\mathrm{Pb}$ (II) onto CLNPs was controlled by chemical adsorption involving chelating, electrostatic forces ion exchange, and valence forces between the adsorbent and adsorbate. 
Table 2. Comparison of the lead adsorption capacity by CLNPs and other adsorbents.

\begin{tabular}{ccccccc}
\hline Adsorbent & $\mathbf{T}\left({ }^{\mathbf{C}} \mathbf{C}\right)$ & Time $(\mathbf{m i n})$ & $\mathbf{p H}$ & $\mathbf{K}_{\mathbf{2}}$ & $\mathbf{Q}_{\mathbf{e}}(\mathbf{m g} / \mathbf{g})$ & Reference \\
\hline Zeolite A & 25 & 30 & 7.5 & - & 213.0 & {$[28]$} \\
Commercial active carbon & 25 & 360 & 6.0 & 0.005 & 29.2 & {$[29]$} \\
Pb-ITMCB & 40 & 480 & 6.0 & $2.9 \times 10^{-4}$ & 259.7 & {$[30]$} \\
Lignosulfonate sphere & 30 & 150 & 5.0 & 0.02 & 27.1 & {$[17]$} \\
Lignin-grafted carbon nanotubes & 25 & 60 & 5.8 & 0.03 & 235.0 & {$[31]$} \\
Carboxymethylation formic lignin & 30 & - & 6.0 & - & 107.5 & {$[16]$} \\
CLNPs & 30 & 180 & 6.03 & 0.0544 & 333.26 & This study \\
\hline
\end{tabular}

Table 3. Kinetic parameters for $\mathrm{Pb}(\mathrm{II})$ adsorption onto CLNPs.

\begin{tabular}{|c|c|c|c|c|c|c|}
\hline \multirow{2}{*}{ Sample } & \multicolumn{3}{|c|}{ Pseudo-First-Order Kinetic } & \multicolumn{3}{|c|}{ Pseudo-Second-Order Kinetic } \\
\hline & Qe (mg/g) & $K_{1}\left(1 \min ^{-1}\right)$ & $\mathbf{R}^{2}$ & Qe (mg/g) & $K_{2}(g / m g$ min $)$ & $\mathbf{R}^{2}$ \\
\hline CLNPs & 304.0 & 1.08 & 0.6013 & 350.9 & 0.0544 & 0.9991 \\
\hline
\end{tabular}

Langmuir [32] and Freundlich [33] isotherm models were applied to fitting $\mathrm{Pb}$ (II) adsorption data. The model can be represented by Equations (5) and (6):

$$
\text { Langmuir : } \frac{C_{e}}{Q_{e}}=\frac{C_{e}}{Q_{\max }}+\frac{1}{Q_{\max } b}
$$

$$
\text { Freundlich : } \log Q_{e}=\log K_{F}+\frac{1}{n} \log C_{e}
$$

where $C_{e}(\mathrm{mg} / \mathrm{L})$ is the equilibrium concentration, $Q_{e}(\mathrm{mg} / \mathrm{g})$ is the equilibrium adsorption capacity, $b(\mathrm{~L} / \mathrm{mg})$ is the Langmuir constant, $Q_{\max }(\mathrm{mg} / \mathrm{g})$ is the maximum adsorption capacity, and $K_{F}(\mathrm{mg} / \mathrm{g})$ and $n$ are the Freundlich constants. The adsorption isotherms at different initial concentration in the range of $20-160 \mathrm{mg} / \mathrm{L}$ were collected. It can be seen from Figure 9 and Table 4 that the adsorption amounts of $\mathrm{Pb}$ (II) by CLNPs increased significantly with the increase in $\mathrm{Pb}$ (II) concentrations until a stable level was reached. The sharp increase in adsorption capacity was observed at low concentrations due to excessive active sites and strong electrostatic attraction, chelating forces for mass transfer. Compared to the Freundlich model $\left(R^{2}=0.448\right)$, the Langmuir model provided better fitting results $\left(R^{2}=0.973\right)$. The experimental data agreed well with the Langmuir adsorption experiment, indicating that lead ions were adsorbed on the surface of CLNPs by a monolayer pattern.

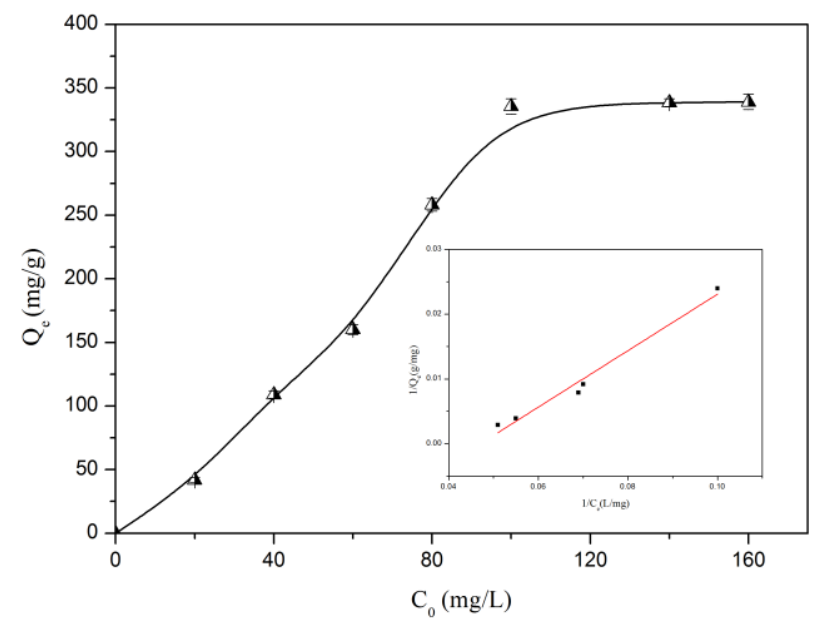

Figure 9. Isotherms of $\mathrm{Pb}(\mathrm{II})$ adsorption on CLNPs. The inset shows the fitting results of the Langmuir model for $\mathrm{Pb}$ (II) adsorption (CLNP dosage $=15 \mathrm{mg} / 50 \mathrm{~mL}$, temperature $=30^{\circ} \mathrm{C}, \mathrm{pH}=6.03$ ). 
Table 4. Freundlich and Langmuir isotherm model parameters for the adsorption of $\mathrm{Pb}(\mathrm{II})$ onto CLNPs.

\begin{tabular}{ccccccc}
\hline \multirow{2}{*}{ Sample } & \multicolumn{3}{c}{ Langmuir Model } & \multicolumn{3}{c}{ Freundlich Model } \\
\cline { 2 - 7 } & $\mathbf{B}(\mathbf{L} / \mathbf{m g})$ & $\mathbf{Q m a x}(\mathbf{m g} / \mathbf{g})$ & $\mathbf{R}^{\mathbf{2}}$ & $\mathbf{n}$ & $\mathbf{K}_{\mathbf{F}}(\mathbf{m g} / \mathbf{g})$ & $\mathbf{R}^{\mathbf{2}}$ \\
\hline CLNPs & 0.1734 & 312.5 & 0.973 & 2.86 & 63.09 & 0.448 \\
\hline
\end{tabular}

In order to clarify the adsorption mechanism of Pb(II) onto CLNPs, XPS analysis of metal-loaded CLNP was performed. Figure 10 shows the XPS spectra of CLNPs before and after adsorption of heavy metals. In addition to the characteristic peaks of C1s $(283.82 \mathrm{eV})$ and $\mathrm{O} 1 \mathrm{~s}(530.95 \mathrm{eV})$ in CLNPs, the characteristic peak of Pb4f was also detected in the XPS full-spectrum trace of CLNPs after adsorption of heavy metals, which was $139.40 \mathrm{eV}$. This indicated that heavy metal ions had been successfully adsorbed onto the surface of CLNPs. The O1s peaks of CLNPs that had adsorbed heavy metal were fitted (Figure 10). In the spectrum of O1s, characteristic peaks of oxygen-containing groups $\left(\mathrm{COO}^{-}, \mathrm{C}=\mathrm{O}\right.$, and $\left.\mathrm{C}-\mathrm{OH}\right)$ appeared at 531.34 and $530.15 \mathrm{eV}$. A comparison of the spectra of Ols before and after adsorption of heavy metals by CLNPs showed that the binding energies of the two characteristic peaks of $\mathrm{O} 1 \mathrm{~s}$ were increased ( 532.2 and $530.57 \mathrm{eV}$, respectively), which indicated that the oxygen atoms on the surface of CLNPs formed a coordination structure with $\mathrm{Pb}$ (II). It was formed by the chelation of $\mathrm{COO}^{-}, \mathrm{C}=\mathrm{O}$, and $\mathrm{C}-\mathrm{OH}$ groups with $\mathrm{Pb}(\mathrm{II})$, as shown in Figure 11. This indicated that CLNPs adsorbed heavy metal ions in water by chemical adsorption, which is in agreement with the analysis of kinetic fitting.
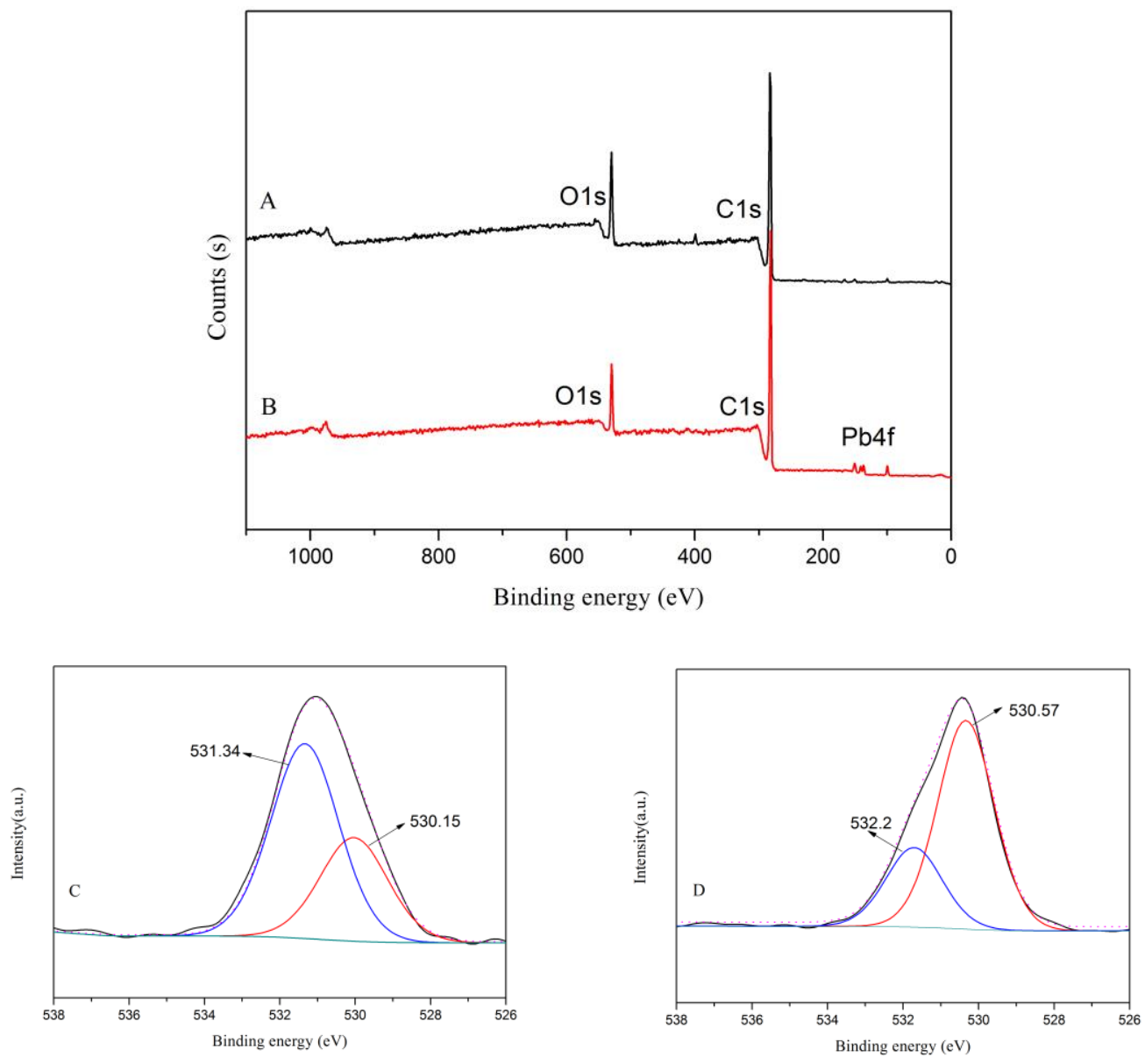

Figure 10. The typical XPS wide scan spectra of CLNPs before (A) and after (B) Pb(II) adsorption. O1s spectra of CLNPs before (C) and after (D) $\mathrm{Pb}$ (II) adsorption. 

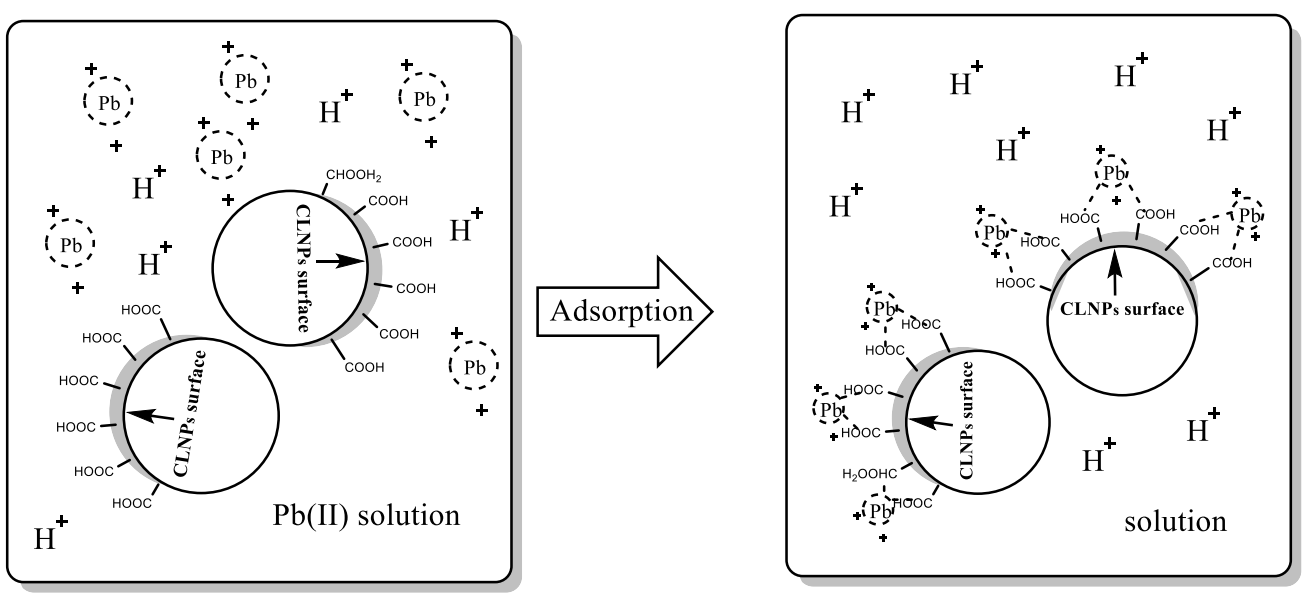

Figure 11. A potential mechanism of $\mathrm{Pb}(\mathrm{II})$ adsorption on CLNPs.

To investigate regeneration and the reusability of CLNPs, five adsorption-desorption cycles were performed on $\mathrm{Pb}$ (II). Regeneration of the lead-loaded CLNPs can be realized by desorbing with $\mathrm{HNO}_{3}$ solution $(0.1 \mathrm{M})$, neutralizing with $\mathrm{NaOH}(0.1 \mathrm{M})$, and then washing. As displayed in Figure 12, CLNPs had a good stability for adsorption of $\mathrm{Pb}(\mathrm{II})$. After five consecutive adsorption-desorption cycles, there was only a $15.0 \%$ loss in adsorption capacity. After 10 consecutive adsorption-desorption cycles, the adsorption capacity loss was $27.0 \%$. This has great practical guiding value for the recycling performance of materials. The test results show that CLNPs can be used as an environmentally friendly and low-cost water purification adsorbent and that $\mathrm{Pb}$ (II) has good recyclability on CLNP, which is beneficial for practical applications.

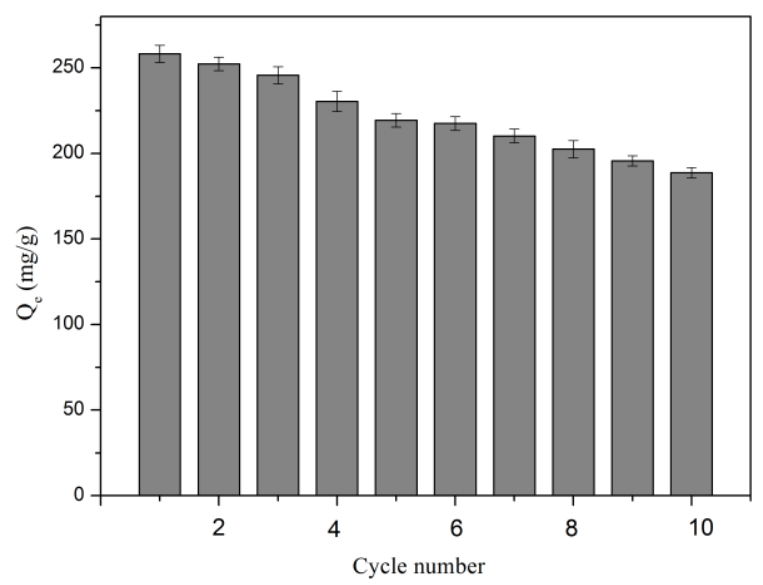

Figure 12. $\mathrm{Pb}$ (II) adsorption capacity of CLNPs at different regeneration cycles (CLNP dosage $=15$ $\mathrm{mg} / 50 \mathrm{~mL}, \mathrm{C}_{0}=100 \mathrm{mg} / \mathrm{L}$, temperature $=30^{\circ} \mathrm{C}, \mathrm{pH}=6.03$ ).

\section{Conclusions}

In this work, eco-friendly and recyclable lignin nanospheres for lead removal were synthesized by the regulation of carboxyl-functionalized alkali lignin and ionic liquid interface. The CLNP adsorbent with higher carboxyl content $(1.8 \mathrm{mmol} / \mathrm{g})$ and surface area $\left(8.63 \mathrm{~m}^{2}\right)$ had an average diameter of 73.9 $\mathrm{nm}$, which is significantly superior to the traditional raw lignin.

The CLNPs showed a high lead adsorption capacity $(333.26 \mathrm{mg} / \mathrm{g})$ and removal efficiency $(98.5 \%)$. The adsorption kinetics of lead followed the pseudo-second-order model, and the adsorption process was close to the chemisorption process through monolayer adsorption. Their main adsorption mechanism was chelation between CLNPs and lead ions. Moreover, the adsorbed $\mathrm{Pb}$ (II) metal ion could be easily desorbed from CLNP adsorbent using $0.1 \mathrm{M} \mathrm{HNO}_{3}$ solution. The CLNPs had 
good reusability for adsorption of metal ions, which means it has great potential for industrial applications in wastewater treatments. However, wastewater has complex components of inorganic salts, organic matters, and heavy metals ions, which is far different from the ideal or real wastewater. CLNPs therefore still have significant room for improvement in terms of practical applications.

Author Contributions: Conceptualization, C.L. and Y.H.; methodology, C.L.; software, C.L.; formal analysis, C.L.; investigation, C.L.; writing-original draft preparation, C.L.; writing-review and editing, C.L. and Y.H.; supervision, Y.L.; project administration, Y.L.; funding acquisition, Y.L.

Funding: This research was funded by the National Key R\&D project of China, grant number 2017YFB0307901 and the National Natural Science Foundation of China, grant number 21476091.

Acknowledgments: The authors wish to thank Analytical and Test center of South China University of Technology for the XPS, SEM and NMR Testing.

Conflicts of Interest: There are no conflict to declare.

\section{References}

1. Klapiszewski, Ł.; Siwińskastefańska, K.; Kołodyńska, D. Preparation and characterization of novel TiO $2 /$ lignin and $\mathrm{TiO}_{2}-\mathrm{SiO}_{2}$ /lignin hybrids and their use as functional biosorbents for $\mathrm{Pb}(\mathrm{II})$. Chem. Eng. J. 2017, 314, 169-181. [CrossRef]

2. Dang, V.Q.; Kim, J.K.; Sarawade, P.B.; Dang, H.T.; Kim, H.T. Preparation of amino-functionalized silica for copper removal from an aqueous solution. J. Ind. Eng. Chem. 2012, 18, 83-87. [CrossRef]

3. Erdem, E.; Karapinar, N.; Donat, R. The removal of heavy metal cations by natural zeolites. J. Colloid Interface Sci. 2004, 280, 309-314. [CrossRef] [PubMed]

4. Dabrowski, A.; Hubicki, Z.; Podkościelny, P.; Robens, E. Selective removal of the heavy metal ions from waters and industrial wastewaters by ion-exchange method. Chemosphere 2004, 56, 0-106. [CrossRef] [PubMed]

5. Liu, Z.; Luo, F.; Ju, X.J.; Xie, R.; Sun, Y.M.; Wang, W.; Chu, L.Y. Gating membranes for water treatment: Detection and removal of trace $\mathrm{Pb}^{2+}$ ions based on molecular recognition and polymer phase transition. J. Mater. Chem. A 2013, 1, 9659-9671. [CrossRef]

6. Li, Z.; Ge, Y. Application of Lignin and Its Derivatives in Adsorption of Heavy Metal Ions in Water: A Review. ACS Sustainable Chem. Eng. 2018, 6, 7181-7192. [CrossRef]

7. Yang, S.; Kim, H.; Narayanan, S.; Mckay, I.S.; Wang, E.N. Dimensionality effects of carbon-based thermal additives for microporous adsorbents. Mater. Des. 2015, 85, 520-526. [CrossRef]

8. Ge, Y.; Li, Q.; Li, Z. Lignin microspheres: An effective and recyclable natural polymer-based adsorbent for lead ion removal. Mater. Des. 2016, 95, 141-147. [CrossRef]

9. Geng, X.; Zhang, Y.; Li, J.; Lei, Y.; Hamel, J.; Giummarella, N.; Henriksson, G.; Zhang, L.; Zhu, H. Bioinspired Ultrastable Lignin Cathode via Graphene Reconfiguration for Energy Storage. ACS Sustainable Chem. Eng. 2017, 5, 3553-3561. [CrossRef]

10. Zhang, X.; Tu, M.; Paice, M.G. Routes to Potential Bioproducts from Lignocellulosic Biomass Lignin and Hemicelluloses. BioEnergy Res. 2011, 4, 246-257. [CrossRef]

11. Varanasi, P.; Singh, P.; Auer, M.; Adams, P.D.; Simmons, B.A.; Singh, S. Survey of renewable chemicals produced from lignocellulosic biomass during ionic liquid pretreatment. Biotechnol. Biofuels 2013, 6, 14. [CrossRef] [PubMed]

12. Li, Z.; Zhang, J.; Li, Q.; Ge, Y. Enhancing antioxidant performance of lignin by enzymatic treatment with laccase. ACS Sustainable Chem. Eng. 2018, 6, 2591-2595. [CrossRef]

13. Li, Z.; Yan, K.; Ge, Y. Synthesis of porous lignin xanthate resin for $\mathrm{Pb}^{2+}$ removal from aqueous solution. Chem. Eng. J. 2015, 270, 229-234. [CrossRef]

14. Wu, Y.; Zhang, S.Z.; Guo, X.Y.; Huang, H.L. Adsorption of chromium(III) on lignin. Bioresour. Technol. 2008, 99, 7709-7715. [CrossRef] [PubMed]

15. Dizhbite, T.; Jashina, L.; Dobele, G.; Andersone, A.; Evtuguin, D.; Bikovens, O.; Telysheva, G. Polyoxometalate (POM)-aided modification of lignin from wheat straw biorefinery. Holzforschung 2013, 67, 539-547. [CrossRef]

16. Peternele, W.S.; Winkler-Hechenleitner, A.A.E.; Gomez Pineda, A. Adsorption of Cd(II) and Pb(II) onto functionalized formic lignin from sugar cane bagasse. Bioresour. Technol. 1999, 68, 95-100. [CrossRef] 
17. Li, Z.; Ge, Y.; Liang, W. Fabrication of a green porous lignin-based sphere for the removal of lead ions from aqueous media. J. Hazard. Mater. 2015, 285, 77-83. [CrossRef]

18. Liu, C.; Li, Y.; Hou, Y. A simple environment-friendly process for preparing high-concentration alkali lignin nanospheres. Eur. Polym. J. 2019, 112, 15-23. [CrossRef]

19. Peng, W.X.; Ren, J.L.; Zhong, L.X.; Cao, X.F.; Sun, R.C. Microwave-induced synthesis of carboxymethyl hemicelluloses and their rheological properties. J. Agric. Food Chem. 2011, 59, 570-576. [CrossRef]

20. Cerrutti, B.M.; Souza, C.S.D.; Castellan, A.; Ruggieroba, R. Carboxymethyl lignin as stabilizing agent in aqueous ceramic suspensions. Ind. Crops Prod. 2012, 36, 108-115. [CrossRef]

21. Liu, C.; Li, Y.; Hou, Y. Basicity Characterization of Imidazolyl Ionic Liquids and Their Application for Biomass Dissolution. Int. J. Chem. Eng. 2018, 2018, 1-8. [CrossRef]

22. You, T.T.; Mao, J.Z.; Yuan, T.Q.; Wen, J.L.; Xu, F. Structural Elucidation of the Lignins from Stems and Foliage of Arundo donax Linn. J. Agric. Food Chem. 2013, 61, 5361-5370. [CrossRef] [PubMed]

23. Wang, K.; Cao, Y.; Wang, X.; Castro, M.A.; Fan, Q. Rod-shape porous carbon derived from aniline modified lignin for symmetric supercapacitors. J. Power Sources 2016, 307, 462-467. [CrossRef]

24. Xiong, F.; Chu, F.; Li, G.; Wang, S.; Qin, T.; Han, Y.; Chen, Y. Preparation and formation mechanism of size-controlled lignin nanospheres by self-assembly. Ind. Crops Prod. 2017, 100, 146-152. [CrossRef]

25. Jin, C.; Zhang, X.; Xin, J.; Liu, G.; Chen, J.; Wu, G.; Liu, T.; Zhang, J.; Kong, Z. Thiol-Ene Synthesis of Cysteine-Functionalized Lignin for the Enhanced Adsorption of $\mathrm{Cu}(\mathrm{II})$ and $\mathrm{Pb}(\mathrm{II})$. Ind. Eng. Chem. Res. 2018, 57, 7872-7880. [CrossRef]

26. Tseng, R.L.; Wu, F.C.; Juang, R.S. Characteristics and applications of the Lagergren's first-order equation for adsorption kinetics. J. Taiwan Inst. Chem. Eng. 2010, 41, 661-669. [CrossRef]

27. Ho, Y.S.; Mckay, G. Sorption of dyes and copper ions onto biosorbents. Process Biochem. 2003, 38, $1047-1061$. [CrossRef]

28. Ulla, W.; Carsten, H.; Gerhard, F.; Rainer, S. Removal of heavy metals from mine waters by natural zeolites. Environ. Sci. Technol. 2005, 39, 4606-4613. [CrossRef]

29. Kołodyńska, D.; Krukowska, J.; Thomas, P. Comparison of Sorption and Desorption Studies of Heavy Metal Ions From Biochar and Commercial Active Carbon. Chem. Eng. J. 2017, 307, 353-363. [CrossRef]

30. Liu, B.; Chen, W.; Peng, X.; Cao, Q.; Wang, Q.; Wang, D.; Meng, X.; Yu, G. Biosorption of lead from aqueous solutions by ion-imprinted tetraethylenepentamine modified chitosan beads. Int. J. Biol. Macromol. 2016, 86, 562-569. [CrossRef]

31. Li, Z.; Chen, J.; Ge, Y. Removal of Lead Ion and Oil Droplet from aqueous solution by Lignin-Grafted Carbon Nanotubes. Chem. Eng. J. 2017, 308, 809-817. [CrossRef]

32. Armbruster, M.H.; Austin, J.B. The Adsorption of Gases on Plane Surfaces of Mica. J. Am. Chem. Soc. 2002, 60, 467-475. [CrossRef]

33. Gubbuk, İ.H.; Gup, R.; Kara, H.; Ersoz, M. Adsorption of Cu(II) onto silica gel-immobilized Schiff base derivative. Desalination 2009, 249, 1243-1248. [CrossRef]

Sample Availability: Samples of the compounds are available from the authors.

(C) 2019 by the authors. Licensee MDPI, Basel, Switzerland. This article is an open access article distributed under the terms and conditions of the Creative Commons Attribution (CC BY) license (http://creativecommons.org/licenses/by/4.0/). 